\title{
Wind pressure acting on greenhouses: A review
}

\author{
Cong Wang, Bo Nan, Tieliang Wang, Yikui Bai, Yuqing Li* \\ (College of Water Conservancy, Shenyang Agricultural University, Shenyang 110866, China)
}

\begin{abstract}
Greenhouses are widely used in agricultural and horticultural production. With the characteristics of lightweight, small stiffness and high flexibility, greenhouses are sensitive to wind loads. In the calculation of wind loads, the wind pressure coefficient $(C p)$ is essential. The rationality of the value directly affects the safety and economy of greenhouses. Therefore, the $C p$ values estimation is one of the most important issues in the design of greenhouses. In order to make full use of the existing research results, in this study, three main methods for estimating $C p$ values were analyzed, namely, full-scale field experiment, wind tunnel experiment and numerical simulation. Five factors influencing the $C p$ values were then reviewed including greenhouse design parameters, greenhouse group, overhanging eaves, ventilation and wind direction. Based on the existing researches, suggestions for future development and research work were also put forward. Owing to the flexibility and deformability of greenhouses, the fluid-solid coupling method should be used to analyze the effects of vibrations on wind pressures. The interaction of building parameters (such as the number of spans, ridge height, roof shape and slope angle) and terrain around the greenhouse should be taken into consideration comprehensively. The destructive vortices occurred on the greenhouse should be further investigated.
\end{abstract}

Keywords: computational fluid dynamics, greenhouse, wind pressure coefficients, wind tunnel, influence factors DOI: $10.25165 /$ j.ijabe.20211402.5261

Citation: Wang C, Nan B, Wang T L, Bai Y K, Li Y Q. Wind pressure acting on greenhouses: A review. Int J Agric \& Biol Eng, 2021; 14(2): 1-8.

\section{Introduction}

Greenhouse is a special type of agricultural buildings ${ }^{[1]}$. The primary purpose of a greenhouse is not only to provide and control solar radiation, temperature, carbon dioxide and humidity for various plants, but also resist all kinds of loads generated by extreme natural disasters, such as typhoons, heavy snowstorms, strong winds and hail ${ }^{[2-4]}$. With the characteristics of lightweight, small stiffness and high flexibility, greenhouses are quite sensitive to wind loads ${ }^{[5,6]}$. Therefore, the wind load, as one of the main control loads in the design of greenhouses, plays a crucial role in ensuring the reliability of the structures ${ }^{[7]}$. However, in order to minimize cost, many greenhouses are usually designed with a lower level of security than general building ${ }^{[8-10]}$. In recent years, strong winds caused a large number of greenhouses collapse, resulting in economic losses for agricultural production ${ }^{[11-13]}$. A study by Ryu et al. ${ }^{[14]}$ indicated that the damage rates of typhoons and strong winds for 17 administrative districts in South Korea are $46.4 \%$ and $2.5 \%$, respectively. And the average damage index of film plastic greenhouse is 0.66 . Therefore, in order to have a safe, economical, durable and cost-effective greenhouse structure, a reliable structural wind resistance design method is indispensable.

Received date: $2019-07-03 \quad$ Accepted date: 2020-12-15

Biographies: Cong Wang, $\mathrm{PhD}$ candidate, research interests: agricultural facilities and environmental engineering, Email: 2020200010@stu.syau.edu.cn; Bo Nan, $\mathrm{PhD}$, Lecturer, research interests: structural engineering, Email: nanbo@syau.edu.cn; Tieliang Wang, PhD, Professor, research interests: agricultural facilities and environmental engineering, Email: tieliangwang@, syau.edu.cn; Yikui Bai, PhD, Professor, research interests: agricultural facilities and environmental engineering, Email: baiyikui@syau.edu.cn.

*Corresponding author: Yuqing Li, Associate Professor, research interests: agricultural facilities and environmental engineering. College of Water Conservancy, Shenyang Agricultural University, No.120, Dongling Road, Shenhe District, Shenyang 110866, China. Tel: +86-13940388634, Email: lyq7707@syau.edu.cn.
There are two major design methods for greenhouses to estimate and ensure wind-resistant performance: quasi-static design method and fluctuating wind pressure design method. Equivalent static wind loads are used in the former method ${ }^{[15]}$. In this method, many researches have been conducted to study the wind-resistant performance of different types of greenhouses ${ }^{[16-20]}$. Though this method is convenient for structural engineers, it cannot reflect the dynamic characteristics of wind loads ${ }^{[21]}$. Recently, the fluctuating wind pressure design method has been widely used to investigate the different aspects of wind vibration effects on greenhouse structures, for instance, fluid-structure interaction ${ }^{[22]}$, fatigue analysis ${ }^{[23]}$, dynamic collapse analysis ${ }^{[24]}$ and strength testing ${ }^{[25,26]}$. These results showed that the effects of fluctuating winds on dynamic responses of greenhouse structures are more dangerous than the average wind.

Whether quasi-static or fluctuating wind pressure design method, it must start with wind loads ${ }^{[27]}$. In the calculation of wind loads, the $C p$, which is defined as the ratio of static pressure difference to the design velocity pressure, is essential ${ }^{[28-30]}$. The rationality of the value can directly affect the safety and economy of greenhouses ${ }^{[31]}$. Therefore, the $C p$ values estimation is one of the most important issues in the design of greenhouses ${ }^{[32]}$. In order to make full use of the research results, in this study, three main methods for estimating $C p$ values and five factors influencing the distribution are summarized. Suggestions for future development and research work are also put forward. It is hoped that this review should provide a reference for estimating $C p$ values and improving the wind-resistant performance of greenhouse structures.

\section{Main methods for wind pressure estimation}

\subsection{Full-scale field experiment}

Full-scale field experiment is that using anemometers, wind pressure sensors and other instruments to assess the aerodynamic and dynamic properties of buildings ${ }^{[33]}$. In the last several 
decades, a number of full-scale field experiments have been conducted to estimate the $C p$ values of different types of greenhouses. And the main experiment parameters of the full-scale field experiment greenhouses are listed in Table 1. These experiments provided a lot of quantitative data for the wind-resistant design of greenhouse structures. These data are also significant for verifying the numerical simulation results in later research. For example, the data obtained by Hoxey and Richardson ${ }^{[34]}$ were used to validate the validity of the numerical model developed by Mathews and Meyer ${ }^{[35,36]}$.

Table 1 Main parameters of the full-scale field experiment greenhouses

\begin{tabular}{|c|c|c|c|c|c|c|}
\hline Greenhouse type & $\mathrm{Span} / \mathrm{m}$ & Length $/ \mathrm{m}$ & Ridge height $/ \mathrm{m}$ & Measurement points & Measuring time/s & References \\
\hline Venlo type & 6.4 & 21.3 & 3.9 & 48 & 240 & \multirow{5}{*}[37]{} \\
\hline Venlo type & 3.2 & 63.0 & 3.1 & 48 & 240 & \\
\hline Venlo type & 6.6 & 79.6 & 4.0 & 48 & 240 & \\
\hline Venlo type & 12.8 & 39.6 & 7.1 & 24 & 240 & \\
\hline Venlo type & 6.4 & 88.8 & 3.9 & 48 & 240 & \\
\hline Tunnel mono-span & 7.3 & 28.1 & 2.8 & 44 & 240 & \multirow{6}{*}[34,39]{} \\
\hline Tunnel mono-span & 6.3 & 24.4 & 3.1 & 44 & 240 & \\
\hline Tunnel mono-span & 6.3 & 24.4 & 3.0 & 44 & 240 & \\
\hline Arch type with 4 spans & 6.2 & 29.4 & 3.3 & 44 & 240 & \\
\hline Arch type with 4 spans & 6.1 & 36.7 & 3.2 & 44 & 240 & \\
\hline Arch type with 5 spans & 4.4 & 36.5 & 3.1 & 66 & 240 & \\
\hline Even-span type & 9.3 & 14.5 & 7.2 & 44 & 240 & [40] \\
\hline Tunnel mono-span & 6 & 24.4 & 3 & 43 & 240 & {$[41]$} \\
\hline Arch type mono-span & 9 & 22 & 3.1 & 44 & 240 & {$[42]$} \\
\hline
\end{tabular}

Although full-scale field experiment provides a direct and reliable approach to estimating the $C p$ values of greenhouses, there are still some limitations: 1) It is difficult to repeat field experiments because the meteorological conditions change randomly; 2) Only a few results can be used due to the limited number of measurement points; 3 ) It can only be carried out after the construction of the greenhouse; 4) The results cannot be used if the surrounding environment of the greenhouse changes in later research; 5) The instruments are expensive and the test cycle is long. Thus, this method is not widely used in later research.

\subsection{Wind tunnel experiment}

To overcome the limitations of full-scale field experiment, wind tunnel experiment is considered to be the most accurate method for estimating wind loads ${ }^{[43]}$. Based on the principles of similarity, the wind loads acting on greenhouses can be obtained using scaled models. And it has shown various advantages: 1) Grilles, blocks, carpets and spires can be effectively used to simulate the wind field for different aerodynamic researches ${ }^{[44]} ; 2$ ) It can avoid the influence of external environment because of the enclosed experiment environment; 3 ) The experimental operation is continuous, simple, safe and high efficiency; 4) The experimental results are more accurate.

Therefore, a large number of wind tunnel experiments have been conducted to estimate the wind pressure acting on greenhouses. Among these studies, Robertson et al. ${ }^{[45]}$ conducted a 1:2 scale model of arched and flat roof structures to study the influences of porous cladding on wind pressure. The results showed that the porous cladding could expand the positive pressure area on the windward roofs, resulting in increased overall drag loadings. Considering the influences of Reynolds number and different aspect ratios, an improved pressure model was proposed by Qiu et al. ${ }^{[46]}$ to estimate the $C p$ values of cylindrical and spherical roofs. Though the experimental-scaled models were not agricultural facilities, the results can be used as a reference for the design of arch type greenhouses. In order to secure the structural safety of greenhouse built on coastal reclaimed land, the $C p$ values of five typical greenhouses used in Korea (1-2W, even-span, three-quarter, peach and mono-span type) were obtained by Ha et al. ${ }^{[47]}$ and Kwon et $\mathrm{al}^{[48]}$. These results were also used for validating the accuracy of the computational fluid dynamics (CFD) models developed by Kim et al ${ }^{[49]}$. The comparison between wind tunnel experiments and numerical results demonstrated that the CFD technique could for estimate the $C p$ values of greenhouse accurately.

\subsection{Numerical simulation}

Though wind tunnel experiments have been widely used as an accurate alternative for estimating wind pressure acting on greenhouses, the number of channels for simultaneous measurement is limited and the instruments are expensive if the number of experimental cases is huge. Recently, numerical simulation has been widely used to estimate the $C p$ values of buildings. The numerical simulation method, also known as the numerical wind tunnel method, is to use CFD software to numerically simulate the wind field around the building and solve the wind loads distribution on the building surfaces ${ }^{[50]}$. Over the past decades, the CFD technique has proved its value for wind engineering studies with increasing computing power ${ }^{[51]}$. And it has a series of advantages: 1) Low cost and high efficiency; 2) It is convenient to change the boundary conditions to obtain all the information related to the variables; 3) It can simulate the building in full size without the distortion problems caused by scale models in traditional wind tunnels; 4) The experimental results are visual and easy to understand. 5) It can extract wind pressure values from any point.

Therefore, various numerical simulation studies have been conducted to measure the wind pressure at agricultural facilities. Yv et al. ${ }^{[52]}$ used CFD method to calculate the wind pressure on a three-span plastic greenhouse under three work conditions: 1) side window open; 2) both of the side and top windows open; 3) all windows closed. In order to investigate the influences of aerodynamic properties on wind pressure, based on Forchheimer's law, a tunnel greenhouse covered by four different agricultural nets 
at high wind velocities was simulated by Mistriotis and Castellano $^{[53]}$. The numerical results showed that both the internal air velocity and wind loads on the structure increased with the porous increases. And the numerical results had also been confirmed experimentally by Robertson et al. ${ }^{[5]}$ in a wind tunnel. It has to be mentioned that these models used above were two-dimensional, while the turbulent behavior and wind direction were highly three-dimensional. In order to improve the accuracy of simulation, Kim et al. ${ }^{[49]}$ developed three-dimensional numerical models to estimate the $C p$ values of multi-span greenhouses with consideration of the various environmental conditions. It was found that the results obtained by two-dimensional numerical model were conservative at the leeward side of greenhouses due to the three-dimensional flow. Therefore, further researches are needed to get more accurate $C p$ values on greenhouses with the use of mathematical models of unstable flow in three dimensions.

\section{Wind pressure distribution on greenhouse surface}

\subsection{Influence of geometric parameters on wind pressure}

\subsubsection{Influence of ridge height on wind pressure}

With the increasing demand for large space, the design of higher and larger models of greenhouses is a growing trend ${ }^{[54]}$. A study by Wang and Ding ${ }^{[5]}$ informed that the $C p$ value of windward and leeward was quadratic along with the mutual insert multi-greenhouse's height. At the same time, the separated flow region on the windward roof is proportional to the eaves height, which is about half of the height for a transverse wind ${ }^{[56]}$. With the increase of greenhouse height, the air separation strength becomes strong. And the negative wind pressures (suctions) on the windward roof become larger. Thus, the high wind suctions on the windward roof for taller greenhouses may cause significant increase bending moments on the greenhouse frames, which may cause greenhouse collapse. While on the leeward roofs and walls, the $C p$ values are almost unchanged due to the reattachment of airflow ${ }^{[57]}$. Therefore, as the greenhouse height rises, the anti-overturning design should be carried out to ensure the safety of greenhouses under strong winds.

3.1.2 Influence of roof shape and slope angle on wind pressure

Compared with body structure, greenhouse roofs are easy to be destroyed due to their lightweight and low stiffness ${ }^{[58]}$. Therefore, it is of great significance to clarify the influence of roof shape and slope angle on wind pressure.

With high requirements for lighting, warmth and ventilation, greenhouses are usually designed with such forms of arched roof, single-slope roof, zigzag roof, symmetrical double-slope roof, double-slope roof with skylight, etc. ${ }^{[59,60]}$. The roof shape can affect the flow pattern around the greenhouse and the resultant wind pressure distribution on it. In a large-sized wind tunnel, Kwon et al. ${ }^{[48]}$ carried out an experimental study on 1:20 scale models of four typical single-span greenhouses used in Korea (even-span, three-quarter, peach and mono-span type). It was found that the $C p$ values decreased dramatically near the windward eaves of greenhouses with slope-shaped roofs (even-span, three-quarter and mono-span type). While the values decreased slowly on the greenhouse with arch-shaped roofs (peach type), a similar conclusion was drawn by Kateris et $\mathrm{al}^{[61]}$. The main reason for this difference was the continuity of roofs and walls. On the slope-shaped roofs, the airflow can be separated sharply at the cornice. While on the arch-shaped roofs, the air flow intensity is relatively weak due to the smooth transition connection between walls and roofs. And a study by Fernández-García ${ }^{[62]}$ indicated that the closer to the roof, the higher negative wind pressure would be presented in arched greenhouses. Therefore, more attention should be paid to the position of the edges and corners, where a relatively large pressure difference could cause strong wind loads and bending moments on the greenhouse.

Apart from roof shape, roof slope angle also can affect the wind pressure on greenhouse surfaces. Figure 1 illustrates the effect of roof slope angle on $C p$ values of a double-slope greenhouse when the wind direction is perpendicular to the ridge.

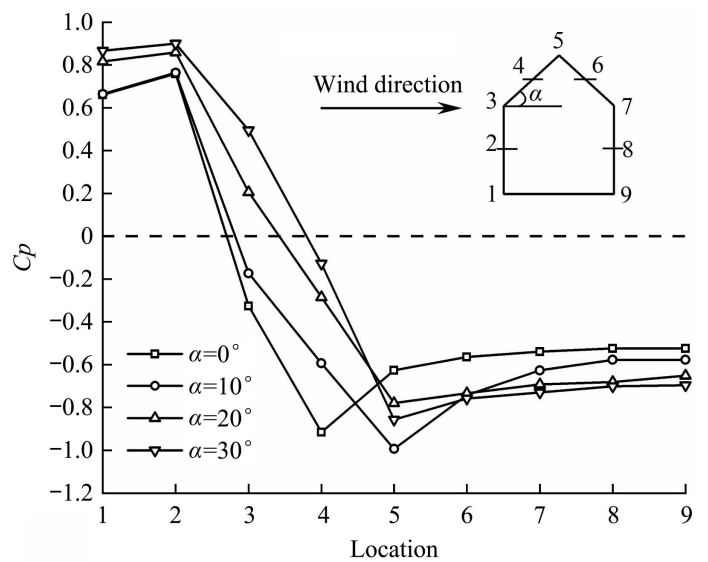

Figure 1 Effects of roof slope angle on the $C p$ values of double-slope greenhouse ${ }^{[63]}$

The $C p$ values at the windward walls are positive due to the pushing effect. And the values have a slight increase when the roofs become steeper. While the values at the leeward regions are negative, since the wind flow is separated from the leading edges and ridges of the roofs. For the greenhouse with a small roof slope angle $\left(\alpha \leq 10^{\circ}\right)$, the $C p$ values on the whole roof are negative. In addition, the values on the windward roofs reduce a lot with increasing roof slope angle. As the slope of the roof increases, the $C p$ values on the windward roofs change from negative to positive. Therefore, more attention should be paid to prevent deformation instability under the combination of positive wind pressure with other loads (such as constant load, snow load, crop load and movable equipment load) ${ }^{[64,65]}$. A study by Xing et al. ${ }^{[6]}$ indicated that the angle of around $20^{\circ}$ was a critical roof angle for slope-shaped roofs. Around this critical angle, the flow pattern on the windward roof changes critically. Therefore, considering the economical rationality of wind-resistance design for double-slope greenhouses, a recommended roof angle is from $20^{\circ}$ to $30^{\circ[63]}$.

\subsubsection{Influence of span number on wind pressure}

The current design method for a multi-span greenhouse is based on the single greenhouse as a basic unit. And the multi-span greenhouse is designed to be assembled by several single greenhouses ${ }^{[67]}$. However, induced flows and pressures on multi-span greenhouses are different from those on a single-span greenhouse ${ }^{[68]}$. Several studies aimed to investigate the influence of the span number on wind pressure are summarized in Table 2 .

Based on the previous studies, it is found that the positive $C p$ values at the windward walls are similar for single-span and multi-span greenhouses, when the wind direction is perpendicular to the greenhouse ridge. While the magnitude of the largest negative $C p$ value appears at the windward roofs of the first or second span, according to the different types of greenhouses. When the number of spans exceeds three, the wind pressure on the middle ones is relatively small in magnitude due to the shielding effect of edge greenhouses. When the wind direction is parallel to 
the ridge, the $C p$ values at the whole roofs decrease as the number of spans increases. Therefore, to acquire a safe and economical multi-span greenhouse structure, the edge and middle greenhouses should be designed respectively.

Although these above studies provided a great deal of information on the wind pressure acting on different types of multi-span greenhouses, these results are not available when the number of spans changes. Therefore, further researches are needed to build a quantitative relationship between wind pressure and the number of spans. Moreover, the main wind direction and wind frequency also should be taken into consideration when setting up a multi-span greenhouse layout in an actual project.

Table 2 Influences of the span number on wind pressure

\begin{tabular}{|c|c|c|c|}
\hline Greenhouse types & Number of spans & Distribution trend of $C p$ values & References \\
\hline South China type & 1,6 & $\begin{array}{l}\text { The } C p \text { values of middle spans were similar when the number of spans exceeds three due to the shielding } \\
\text { effect of the edge greenhouses. }\end{array}$ & {$[69]$} \\
\hline Arch type & $1,3,5,10$ & $\begin{array}{l}\text { When the wind direction is parallel to the greenhouse ridge, the maximum positive } C p \text { value increases with } \\
\text { increasing number of spans. }\end{array}$ & {$[70]$} \\
\hline Venlo type & $1,3,5,10$ & $\begin{array}{l}\text { When the wind direction is perpendicular to the greenhouse ridge, the magnitude of the largest negative } C p \\
\text { value decreases with increasing number of spans. }\end{array}$ & {$[71]$} \\
\hline Duo-pitch type & 30 & $\begin{array}{l}\text { The overall horizontal wind force on multi-span duo-pitch greenhouses increases linearly with increasing } \\
\text { number of spans. }\end{array}$ & {$[72]$} \\
\hline Pointed roof type & $1,3,5,10$ & $\begin{array}{l}\text { The maximum positive } C p \text { value increases as the number of spans increased when the wind direction was } \\
\text { parallel to the greenhouse ridge. }\end{array}$ & {$[73]$} \\
\hline $\begin{array}{c}\text { Wide-span type } \\
\text { 1-2W type } \\
\text { Venlo type }\end{array}$ & $\begin{array}{c}2,4,6,8 \\
2,4,6,8 \\
2,4,6,8,12,16\end{array}$ & $\begin{array}{l}\text { When the wind direction was parallel to the greenhouse ridge, the magnitude of the largest negative } C p \\
\text { value at the roofs decreased as the number of spans increased. }\end{array}$ & {$[74]$} \\
\hline Wide-span type & $1,2,3$ & $\begin{array}{l}\text { The positive } C p \text { values at the windward walls were similar for single-span and multi-span greenhouses. } \\
\text { While the magnitude of the largest negative } C p \text { value was observed at the windward roofs of the first span. }\end{array}$ & {$[75]$} \\
\hline Mono slope type & $1,2,3$ & The magnitude of the largest negative $C p$ value was observed at the windward roofs of the second span. & {$[76]$} \\
\hline
\end{tabular}

\subsection{Influences of group greenhouses on wind pressure}

In a greenhouse park, there are usually a large number of single greenhouses. Compared with an isolated greenhouse, the wind-induced interference effects among greenhouse group are obvious, which will make wind pressures on the target greenhouse be quite different from those on an isolated greenhouse ${ }^{[77]}$. Such interference effects will overestimate wind pressures in some greenhouse areas, and underestimate wind pressures in other greenhouse areas.

Wind-induced interference effects are strongly dependent on arrangement modes, building spacing, wind direction and the number of upstream buildings ${ }^{[78-80]}$. When the wind direction is perpendicular to the ridge and the greenhouses are arranged in parallel, they are mainly subject to the "shielding effect". Airflow characteristics are transformed from independent flow mode to skip flow mode or wake interference flow mode, making the $C p$ values of the rear greenhouse be negative ${ }^{[81]}$. Similar phenomena also can be found in multi-span greenhouses. While when the greenhouses are arranged side by side, they are mainly subject to the "slit effect". Wind speed between greenhouses increases with the decrease of distance. When the greenhouses are arranged multiple in rows and lines, the wind pressures on the outer area of the greenhouse group can be magnified, while the pressures on the middle area of the greenhouse group can be reduced because of the shielding effects ${ }^{[82]}$. Therefore, wind-induced interference effects must be taken into consideration in the structural design stage. For edge greenhouses that bear larger wind pressures, high-strength steel can be used or the arch spacing can be reduced to improve the wind-resistant performance. For middle greenhouses that are less affected by wind pressures, the wind load design criteria could be lowered down to save materials and reduce costs ${ }^{[83]}$.

Although these previous studies have enhanced our understanding of interference effects between greenhouses, they only focused on single factor on the wind pressure distribution of greenhouse groups through wind tunnel or numerical simulation experiments. In the future work, other factors including the effect of the terrain around the greenhouse should be considered comprehensively to provide a basis for the wind-resistant design of group greenhouses.

\subsection{Influences of overhanging eaves on wind pressure}

In areas with heavy rain in summer, some greenhouses have eaves on side walls and gables in order to prevent rainwater from drifting into the greenhouse. Due to the existence of eaves, the wind field around these eaves is rather complicated, which often generates concentrated negative pressures ${ }^{[84]}$. Therefore, a roof overhang is one of the most easily damaged parts of greenhouses during windstorms ${ }^{[85,86]}$. A study by Xie and $\mathrm{Chen}^{[87]}$ informed that the $C p$ values at the downwind gables of South China type greenhouse were proportional to the eaves height. Compared with the double-slope greenhouse without eaves, the incoming flow separated at the top of the windward eaves and then reattached again on the roof, which induced high suctions near the eaves. The results were consistent with those obtained by Guo et al ${ }^{[69]}$.

Although there is a good understanding on the phenomenon of wind pressure acting on eaves and ridges, modeling the complex flow phenomena such as airflow separation, reattachment and vortex shedding is still a problem ${ }^{[88]}$. To overcome this limitation, an alternative approach called large eddy simulation (LES) was used to predict the transient wind pressure value of various structures. LES is more accurate than the Reynolds-averaged Navier-Stokes (RANS) approach since the large eddies contain most of the turbulent energy. And it can simulate fluctuating turbulence structures ${ }^{[8,90]}$. At the same time, other building parameters affecting the wind pressure on roof overhangs should be investigated, such as roof shape, roof slope and eaves geometry. And further work can be done to develop different eave shapes to reduce wind loads.

\subsection{Influence of ventilation on wind pressure}

Greenhouses are designed to provide a suitable environment for the growth of plants annually ${ }^{[91,92]}$. One of the key factors controlling the greenhouse environment is ventilation ${ }^{[93]}$. There are major two types of ventilation: natural ventilation and mechanical ventilation. Natural ventilation is the air exchange based on the difference of temperature and pressure between the 
internal and external of the greenhouse ${ }^{[94]}$. From the perspective of engineering, ventilation not only can change the internal climatic conditions, but also can affect the net wind pressure acting on the structure, which is determined by the difference between the internal and external wind pressure ${ }^{[95]}$. A study by Moriyama et al. ${ }^{[96]}$ indicated that the openings on windward gable walls may increase uplift wind forces on the frames significantly and cause a collapse of greenhouse.

Therefore, it is necessary to study the effects of ventilation on wind pressure. Under open or closed greenhouse roof windows, Xie and Chen ${ }^{[87]}$ tested the wind pressure acting on South China type single-span plastic greenhouse. When the roof windows were open, the wind pressures on the greenhouse roofs and walls were larger than that when the roof windows were closed. And the pressure acting on the roof windows could be 2 to 5 times bigger than that when the roof windows were closed. It was hence better to design the roof windows that can be closed. The roof windows should be closed when encountering with strong winds. While contrary to the above results, Wang et al. ${ }^{[97]}$ carried out wind tunnel tests to investigate the influence of ventilation on the distribution of wind pressure on a mutual inserted multi-greenhouse. The results showed that when the windows were open, the wind pressure on the greenhouse surface was distinctly lower than that when the windows were closed. So, the $C p$ values of closed ventilators should be chosen when computing the wind loads on the structure. The differences between South China type single-span plastic greenhouse and mutual inserted multi-greenhouse pressure distribution can be due to three reasons: different greenhouse shapes, different ventilation positions and different ventilation combinations. Apart from windows' effect on the wind pressure, ventilation opening configurations, wind direction and wind speed also can affect the net wind pressure on greenhouse structure by changing the internal wind pressure ${ }^{[98]}$. $\mathrm{Yi}$ et al. ${ }^{[99]}$ conducted wind tunnel and CFD simulations to investigate the effects of wind speed and wind direction on $C p$ of sidewall opening in a dairy building model. The results indicated that the external pressure was greatly dependent on the wind direction but was almost unaffected by the wind speed and the opening size. However, the dynamic load effects of wind pressures were not included in their study, and the investigations were carried out under Reynolds numbers independent conditions. Therefore, further researches are needed to find out the relationship between ventilation and wind pressure.

\subsection{Influence of wind direction on wind pressure}

Inflow wind direction affects the distribution of wind pressure on the surface of greenhouse structure by generating different destructive vortices. Two typical destructive vortices are columnar vortices and conical vortices (Figure 2 and Figure 3 ).

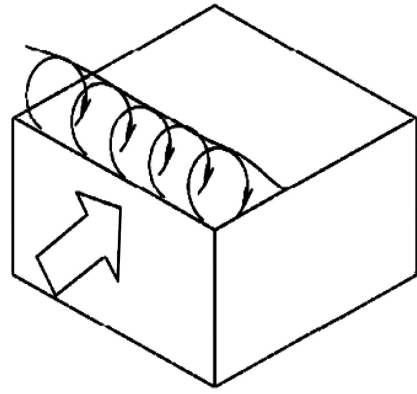

Figure 2 Columnar vortex ${ }^{[100]}$

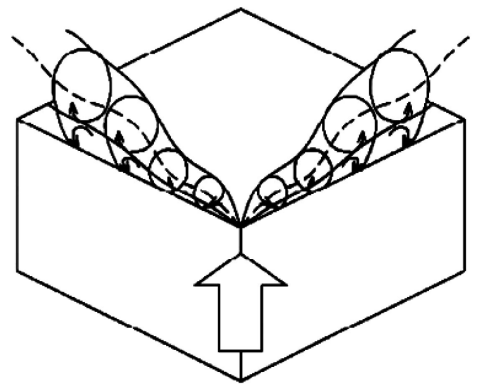

Figure 3 Conical vortex ${ }^{[100]}$

The columnar vortices are formed as a result of the incoming flow perpendicular to the windward front of the greenhouse. The conical vortices are formed by the angle between the incoming flow and the windward leading edge of the greenhouse ${ }^{[101]}$. Thus, it is important to find out the relationship between wind pressure distribution and wind direction. Several studies aimed to investigate the influence of wind direction on wind pressure are summarized in Table 3.

Table 3 Influence of wind direction on wind pressure

\begin{tabular}{|c|c|c|c|}
\hline Greenhouse type & Wind direction & Distribution trend of $\mathrm{Cp}$ values & References \\
\hline $\begin{array}{l}\text { Single-span plastic and } \\
\text { Chinese Solar Greenhouse }\end{array}$ & $0^{\circ}-180^{\circ}$ at an interval of $15^{\circ}$ & $\begin{array}{l}\text { The } C p \text { values on the roof of plastic greenhouse were generally negative, and the } \\
\text { maximum negative } C p \text { value was } 1.49 \text { at a wind direction angle of } 60^{\circ} \text {. }\end{array}$ & {$[102,103]$} \\
\hline Venlo type & $0^{\circ}-90^{\circ}$ at an interval of $30^{\circ}$ & $\begin{array}{l}\text { The oblique wind was the most unfavorable wind condition. The distribution range of } \\
C p \text { values on the surface of the Venlo greenhouse was }-2.2 \text { to } 1.0 \text {. }\end{array}$ & {$[71]$} \\
\hline Arch type & $0^{\circ}-90^{\circ}$ at an interval of $30^{\circ}$ & $\begin{array}{l}\text { Flows in the } 30^{\circ} \text { and } 60^{\circ} \text { directions produced the maximum pressure on the arch type } \\
\text { greenhouse. }\end{array}$ & {$[70]$} \\
\hline Arch type & $0^{\circ}-90^{\circ}$ at an interval of $5^{\circ}$ & $\begin{array}{l}\text { The maximum negative } C p \text { values on the plastic greenhouse appeared in a small area near } \\
\text { the windward ridge-gable corner of the leeward roof at a wind direction angle of } 25^{\circ} \text {. }\end{array}$ & {$[57]$} \\
\hline Pointed roof type & $0^{\circ}-90^{\circ}$ at an interval of $30^{\circ}$ & $\begin{array}{l}\text { The wind from the direction of } 60^{\circ} \text { caused higher wind pressure than that from the } \\
\text { direction of } 30^{\circ} \text {. }\end{array}$ & {$[73]$} \\
\hline Chinese Solar Greenhouse & $0^{\circ}-180^{\circ}$ at an interval of $15^{\circ}$ & $\begin{array}{l}\text { The maximum negative } C p \text { value was } 1.41 \text { at a wind direction angle of } 135^{\circ} \text { and the } \\
\text { critical wind speed of solar greenhouse wind disaster was } 18.9 \mathrm{~m} / \mathrm{s} \text {. }\end{array}$ & {$[104]$} \\
\hline
\end{tabular}

These results have revealed the characteristics of wind pressure under different wind directions. They have provided a theoretical basis for the wind-resistant design of greenhouses. However, they did not further reveal the relationship between destructive vortices and wind pressure distribution. At present, most researches on destructive vortices are concentrated on the field of aviation and high-rise flat roof construction. There have been few studies on the structure of greenhouses. Therefore, more researches on characteristics of vortices, vortex-induced wind pressure and generation mechanism of severe suction under vortices should be investigated. In this way, the vortex destructive effect can be restrained at the source.

\section{Conclusions}

This paper systematically summarized the previous studies on the wind pressure coefficients $(C p)$ value measurements and factors 
affecting wind pressure acting on greenhouses. Although many research results have been obtained, there are still some deficiencies.

(1) Combined with wind tunnel experiment, numerical simulation technology will be an important method for estimating the $C p$ values of greenhouses. At present, rigid models are mostly used in wind tunnel or numerical simulation experiments, which cannot consider the effects of fluid-solid coupling on light and flexible structures ${ }^{[105]}$. Therefore, in further studies, elastic models should be used to take into account the effects of fluid-solid coupling on the wind pressure distribution on the greenhouse surface.

(2) A recommended roof angle for a double-slope greenhouse is from $20^{\circ}$ to $30^{\circ}$. For multi-span greenhouses, the wind pressures acting on the middle ones are similar when the number of spans exceeds three. The wind-induced interference effects and destructive vortices should be taken into account.

(3) Currently, the research on the factors affecting wind pressure on greenhouses only focuses on the greenhouse itself, ignoring the impact of surrounding environment. But the surrounding environment (typical mountain terrain, giant trees, etc.) also has an impact on the wind pressure acting on greenhouses. Therefore, more researches are needed to investigate the effect of the surrounding environment on wind pressure in the future.

\section{Acknowledgements}

This research was supported by National Bulk Vegetable Industry Technology System Post Expert Project (Grant No. CARS-23-C01); Key Research \& Development Projects of Liaoning Province, China (Grant No. 2018103007) and Liaoning Provincial Education Department Fund (Grant No. LSNQN201718).

\section{[References]}

[1] Ding M, Li M M, Shi X D, Zhang P, Jiang X G. Stable bearing capacity calculation of greenhouse structures considering skin effect of covering material. Transactions of the CSAE, 2016; 32(Supp.1): 224-232. (in Chinese)

[2] Lee S-i, Lee J-h, Jeong Y-j, Choi W. Development of a structural analysis model for pipe structures to reflect ground conditions. Biosyst Eng, 2020; 197: 231-244.

[3] Lee S H, Shin K J, Lee H D. Behavior of plastic greenhouses under symmetric loading before and after strengthening with tension ties. Adv Steel Constr, 2018; 14(4): 694-709.

[4] Kang J, Jeon J, Yoon S, Choi W. Failure conditions for stand-alone cold-frame greenhouse under snow loads. Paddy and Water Environment, 2019; 17(4): 651-663.

[5] Kateris D L, Kotsopoulos T A, Fragos V P, Nikita-Martzopoulou C. Numerical estimation of pressure coefficients over single and multispan duo pitched roof greenhouses. Acta Hortic, 2012; 952: 155-161.

[6] Li M, Zhou C J, Yan J Y, Zhang Q S, He F, Yin Y L. Review on anti-wind technologies of plastic tunnel in Japan. Journal of Chinese Agricultural Mechanization, 2016; 37(8): 46-53. (in Chinese)

[7] Yan J Y, Zhou L, Zhou C J, Ding X M, Wei X M, Li M. Method for calculating basic wind pressure of plastic greenhouse. Transactions of the CSAE, 2014; 30(12): 171-176. (in Chinese)

[8] He Y P, Yan J Y, Zhou L. Analyzing plastic greenhouse's partial coefficient for loads in combination of dead loads and wind loads. Transactions of the CSAE, 2016; 32(4): 179-184. (in Chinese)

[9] Pena A, Peralta M, Marin P. Design and testing of a structural monitoring system in an Almería-type tensioned structure greenhouse. Sensors, 2020; 20(1): 258 . doi: 10.3390/s20010258.

[10] Ha T, Kim J, Cho B-H, Kim D-J, Jung J-E, Shin S-H, et al. Finite element model updating of multi-span greenhouses based on ambient vibration measurements. Biosyst Eng, 2017; 161: 145-156.

[11] Briassoulis D, Dougka G, Dimakogianni D, Vayas I. Analysis of the collapse of a greenhouse with vaulted roof. Biosyst Eng, 2016; 151:
495-509.

[12] Yu H, Chen S N, Li Z F, Chen L L, Li X, Li C, et al. Analysis of spatial and temporal characteristics of wind disaster risk of solar greenhouse in Wuqing District of Tianjin. Meteorological and Environmental Sciences, 2019; 42(2): 62-67. (in Chinese)

[13] Yang X F, Liu J, Cao M, Yang G H, Zhang X B, Huang X Y. Structural optimization design of economical steel tube plastic greenhouse with typhoon resistance in tropical region. Journal of Chinese Agricultural Mechanization, 2016; 37(12): 48-52. (in Chinese)

[14] Ryu H R, Choi M K, Cho M W, Yu I H, Kim S Y. Damage index estimation by analysis of meteorological disasters on film plastic greenhouses. Int J Agric \& Biol Eng, 2019; 12(5): 58-63.

[15] Blaise N, Andrianne T, Denoël V. Assessment of extreme value overestimations with equivalent static wind loads. J Wind Eng Indus Aerodyn, 2017; 168: 123-133.

[16] Tamaki M, Shinjyo T, Shikanai T, Tamaki S. Development of truss structure greenhouse materials having lower costs and strength against typhoons. Acta Hortic, 2015; 1107: 31-36.

[17] Saglam C, Guzel M, Cetin N. A greenhouse construction with fiber-reinforced plastic chords and triangular pyramid models. Fresenius Environ Bull, 2018; 27(12): 9447-9452.

[18] Ren J, Wang J, Guo S, Li X, Zheng K, Zhao Z. Finite element analysis of the static properties and stability of a large-span plastic greenhouse. Comput and Electron in Agric, 2019; 165: 104957.

[19] Guan S, Yu H, Zhang Y, Sui Y. Mechanical research on bionic greenhouse skeletons designed from Euryale (Euryale ferox Salisb.) venation distribution based on finite element method. Int Agric Eng J, 2018; 27(2): 82-91.

[20] Yu H, Guan S, Zhang Y, Sui Y. Design of dome greenhouse skeleton based on bionic study on venation distribution of Euryale (Euryale ferox Salisb.) leaf. Int Agric Eng J, 2017; 26(2): 27-35.

[21] Jiang Y C, Bai Y K, Zhou D S, Wang Y G. Numerical simulation of pulsating wind velocity histories and wind pressure histories of plastic greenhouse. J Agric Mechanization Res, 2019; 6: 13-18. (in Chinese)

[22] Lei J Q, Wang D X, Jiang X G, Li B M. Numerical analysis on wind vibration effect on greenhouse structures. J China Agric Univ, 2007; 12(4): 85-89. (in Chinese)

[23] Hur D-J, Kwon S. Fatigue analysis of greenhouse structure under wind load and self-weight. Appl Sci, 2017; 7(12): $1274 . \quad$ doi: 10.3390/app7121274

[24] Wang J L, Guo H, Ren X Q, Sun J H. Global dynamic collapse analysis of single-layer cylindrical reticulated shell in greenhouse under disaster wind loads. Transactions of the CSAE, 2017; 33(9): 195-203. (in Chinese)

[25] Jiang Y C, Bai Y K, Wang Y G, Wang Y, Zhou D S. Wind-induced vibration response of plastic greenhouse structures. J Huazhong Agric Univ, 2018; 37(5): 123-130. (in Chinese)

[26] Jiang Y C, Bai Y K, Wang Y G, Wang Y. Dynamic response analyses of plane frame solar greenhouse considering fluctuating wind speed. J China Agric Univ, 2019; 24(4): 136-147. (in Chinese)

[27] Tong L W, Jin J, Zhou F. Comparative study on calculation of wind loads on greenhouse structures between codes of China and Europe. Transactions of the CSAE, 2013;29(21): 174-181. (in Chinese)

[28] Kim R-w, Lee I-b, Yeo U-h, Lee S-y. Estimating the wind pressure coefficient for single-span greenhouses using an large eddy simulation turbulence model. Biosyst Eng, 2019; 188: 114-135.

[29] Hur D J, Noh J H, Lee H J, Song H W. Evaluation of stress distribution with wind speed in a greenhouse structure. Wind Struct, 2018; 27(5): 347-356.

[30] Kim R-W, Lee I-B, Yeo U-H, Lee S-Y. Evaluation of various national greenhouse design standards for wind loading. Biosyst Eng, 2019; 188: 136-154.

[31] Maraveas C. Wind pressure coefficients on greenhouse structures. Agriculture, 2020; 10(5): 21 . doi: 10.3390/agriculture10050149.

[32] Moriyama H, Sase S, Okushima L, Ishii M. Which design constraints apply to a pipe-framed greenhouse? From perspectives of structural engineering, meteorological conditions, and wind engineering. Jarq-Japan Agricultural Research Quarterly, 2015; 49(1): 1-9.

[33] Chen B, Wu T, Yang Y, Yang Q, Li Q, Kareem A. Wind effects on a cable-suspended roof: Full-scale measurements and wind tunnel based predictions. J Wind Eng Indus Aerodyn, 2016; 155: 159-173.

[34] Hoxey R P, Richardson G M. Measurements of wind loads on full-scale film plastic clad greenhouses. J Wind Eng Indus Aerodyn, 1984; 16: 57-83. 
[35] Mathews E H, Meyer J P. Numerical modelling of wind loading on a film clad greenhouse. Build Environ, 1987; 22(2): 129-134

[36] Mathews E H, Meyer J P. Computation of wind loads on a semicircular greenhouse. J Wind Eng Indus Aerodyn, 1988; 29: 225-233.

[37] Wells D A, Hoxey R P. Measurement of wind loads on full-scale glasshouses. J Wind Eng Indus Aerodyn, 1980; 6: 139-167.

[38] Moran P. Full-scale measurement of wind pressures on a $27.8 \mathrm{~m}$ long single $21.5 \mathrm{~m}$ span agricultural building. J Agric Eng Res, 1981; 26: $55-61$

[39] Hoxey R P, Richardson G M. Wind loads on film plastic greenhouses. J Wind Eng Indus Aerodyn, 1983; 11: 225-237.

[40] Robertson A P, Hoxey R P, Moran P. A full-scale study of wind loads on agricultural ridged canopy roof structures and proposals for design. J Wind Eng Indus Aerodyn, 1985; 21: 167-205

[41] Richardson G M. Wind loads on a full-scale film-plastic clad greenhouse: with and without shelter from a windbreak. J Wind Eng Indus Aerodyn, 1986; 23: 321-331

[42] Richardson G M. Full-scale wind load measurements on a single-span film plastic-clad livestock building. J Agric Eng Res, 1993; 55: 251-264.

[43] Espinoza K, Valera D L, Torres J A, Lopez A, Molina-Aiz F D. An auto-tuning PI control system for an open-circuit low-speed wind tunnel designed for greenhouse technology. Sensors (Basel), 2015; 15(8): 19723-19749.

[44] Kozmar H, Laschka B. Wind-tunnel modeling of wind loads on structures using truncated vortex generators. J Fluids Struct, 2019; 87: 334-353.

[45] Robertson A P, Roux P, Gratraud J, Scarascia G, Castellano S, Dufresne de Virel $\mathrm{M}$, et al. Wind pressures on permeably and impermeably-clad structures. J Wind Eng Indus Aerodyn, 2002; 90: 461-474.

[46] Qiu Y, Sun Y, Wu Y, Tamura Y. Modeling the mean wind loads on cylindrical roofs with consideration of the Reynolds number effect in uniform flow with low turbulence. J Wind Eng Indus Aerodyn, 2014; 129: 11-21.

[47] Ha T, Lee I-B, Hwang H, Ha J. Wind pressure coefficients determination for greenhouse built on a reclaimed land. Acta Hort, 2014; 1037: 1001-1007.

[48] Kwon K-S, Kim D-W, Kim R-W, Ha T, Lee I-B. Evaluation of wind pressure coefficients of single-span greenhouses built on reclaimed coastal land using a large-sized wind tunnel. Biosyst Eng, 2016; 141: 58-81.

[49] Kim R-W, Lee I-B, Kwon K-S. Evaluation of wind pressure acting on multi-span greenhouses using CFD technique, Part 1: Development of the CFD model. Biosyst Eng, 2017; 164: 235-256.

[50] Bendjebbas H, Abdellah-ElHadj A, Abbas M. Full-scale, wind tunnel and CFD analysis methods of wind loads on heliostats: A review. Renewable Sustainable Energy Rev, 2016; 54: 452-472.

[51] Lee I-B, Bitog J P P, Hong S-W, Seo I-H, Kwon K-S, Bartzanas T, et al. The past, present and future of CFD for agro-environmental applications. Comput Electron Agric, 2013; 93: 168-183.

[52] Yv Y H, Wang J P, Ying Y B. Numerical simulation of wind pressure on multi-span plastic greenhouse under multiple work conditions. J Jiangsu Univ, Nat Sci Ed, 2007; 28(5): 373-376. (in Chinese)

[53] Mistriotis A, Castellano S. Airflow through net covered tunnel structures at high wind speeds. Biosyst Eng, 2012; 113(3): 308-317.

[54] Neto J G V, Soriano J. Influence of greenhouse's shape in the structural performance. Acta Hortic, 2017; 1170: 855-860.

[55] Wang J, Ding W M. Simulation of wind pressure distribution on mutual insert multi-greenhouse. Transactions of the CSAM, 2007; 38(9): 90-93. (in Chinese)

[56] Hoxey R P, Robertson A P, Basara B, Younis B A. Geometric parameters that affect wind loads on low-rise buildings: Full-scale and CFD experiments. J Wind Eng Indus Aerodyn, 1993; 50: 243-252.

[57] Moriyama H, Sase S, Uematsu Y, Ishii M, Okushima L. Influence of ridge height of pipe-framed greenhouses on wind pressure coefficients. Trans ASABE, 2015; 58(3): 763-769.

[58] Dougka G, Briassoulis D. Load carrying capacity of greenhouse covering films under wind action: Optimising the supporting systems of greenhouse films. Biosyst Eng, 2020; 192: 199-214.

[59] Sahdev R K, Kumar M, Dhingra A K. A comprehensive review of greenhouse shapes and its applications. Front Energy, 2017; 13(3): 427-438.

[60] Syed A M, Hachem C. Review of construction; geometry; heating, ventilation, and air-conditioning; and indoor climate requirements of agricultural greenhouses. Biosyst Eng, 2019; 44(1): 18-27.

[61] Kateris D L, Fragos V P, Kotsopoulos T A, Martzopoulou A G, Moshou D.
Calculated external pressure coefficients on livestock buildings and comparison with Eurocode 1. Wind Struct, 2012; 15(6): 481-494.

[62] Fernández-García M S, Vidal-López P, Rodríguez-Robles D, Villar-García J R, Agujetas R. Numerical simulation of multi-span greenhouse structures. $\quad$ Agriculture, 2020; 10(11): $499 . \quad$ doi: 10.3390/agriculture10110499.

[63] Lei J Q, Li B M. Numerical simulation of wind pressure on greenhouses with different roof pitches. J China Agric Univ, 2007; 12(6): 93-96.

[64] Nayak A K, Rao K V R. Estimation of wind load on a greenhouse and evaluation of its structural stability. International Journal of Agricultural Engineering, 2014; 7(2): 461-466.

[65] Maraveas C, Tsavdaridis K D. Strengthening techniques for greenhouses AgriEngineering, 2020; 2(1): 37-54

[66] Xing F, Mohotti D, Chauhan K. Study on localised wind pressure development in gable roof buildings having different roof pitches with experiments, RANS and LES simulation models. Build Environ, 2018; 143: 240-257.

[67] Ren Y Z, Wang M J, Saeeda I A, Chen X R, Gao W L. Progress, problems and prospects for standardization of greenhouse-related technologies. Int J Agric \& Biol Eng, 2018; 11(1): 40-48.

[68] Reichrath S, Davies T W. Computational fluid dynamics simulations and validation of the pressure distribution on the roof of a commercial multi-span Venlo-type glasshouse. J Wind Eng Indus Aerodyn, 2002; 90: 139-149.

[69] Guo W D, Xu Y, Zhang T Z. CFD simulation of wind pressure on greenhouse structure. J China Agric Univ, 2005; 10(1): 56-59. (in Chinese)

[70] Cai W Y, Yuan J, Qiao K, Lv J S. Numerical simulation and research on wind pressure of arch-type greenhouse. J Southwest China Norm Univ, Nat Sci Ed, 2014; 39(10): 92-95. (in Chinese)

[71] Tao Y, Lv J S, Yuan J. Numerical simulative research on Venlo-type greenhouse wind load character. J Agric Mechanization Res, 2014; 6: 45-48. (in Chinese)

[72] Bronkhorst A J, Geurts C P W, van Bentum C A, van der Knaap L P M, Pertermann I. Wind loads for stability design of large multi-span duo-pitch greenhouses. Frontiers in Built Environment, 2017; 3. doi: 10.3389/fbuil.2017.00018.

[73] Yan F E, Li W Q. On wind pressure on greenhouses with a pointed roof with numerical simulation. J Southwest China Norm Univ, Nat Sci Ed, 2017; 42(2): 127-132. (in Chinese)

[74] Kim R-W, Hong S-W, Lee I-B, Kwon K-S. Evaluation of wind pressure acting on multi-span greenhouses using CFD technique, Part 2: Application of the CFD model. Biosyst Eng, 2017; 164: 257-280.

[75] Chu C-R, Lan T-W, Tasi R-K, Wu T-R, Yang C-K. Wind-driven natural ventilation of greenhouses with vegetation. Biosyst Eng, 2017; 164: 221-234.

[76] Chu C-R, Lan T-W. Effectiveness of ridge vent to wind-driven natura ventilation in monoslope multi-span greenhouses. Biosyst Eng, 2019; 186: 279-292.

[77] Ntinas G K, Dados I, Kateris D, Fragos V P, Kotsopoulos T A. CFD study of external pressure coefficient over two greenhouses with parabolic roofs in tandem arrangement with numerical approximation. Acta Hortic, 2017; 1170: 145-150.

[78] Kim Y C, Tamura Y, Yoon S-W. Proximity effect on low-rise building surrounded by similar-sized buildings. J Wind Eng Indus Aerodyn, 2015; 146: $150-162$.

[79] Chen B, Cheng H, Kong H, Chen X, Yang Q. Interference effects on wind loads of gable-roof buildings with different roof slopes. J Wind Eng Indus Aerodyn, 2019; 189: 198-217.

[80] Li G, Gan S, Li Y, Wang L. Wind-induced interference effects on low-rise buildings with gable roof. J Wind Eng Indus Aerodyn, 2017; 170: 94-106.

[81] Moriyama H, Sase S, Uematsu Y, Yamaguchi T. Wind tunnel study of the interaction of two or three side-by-side pipe-framed greenhouses on wind pressure coefficients. Transactions of the ASABE, 2010; 53(2): 585-592.

[82] Wu K, Wang S J, Zhang G P, Wei M, Liu F S, Lü X. Wind-induced interference effects and wind pressure characteristics of arched plastic greenhouses. Transactions of the CSAE, 2019; 35(15): 165-174. (in Chinese)

83] Jing W Y, Yuan J, Qiao K. Numerical simulation and research on wind pressure of arch-type plastics greenhouses based on computational fluid dynamics. Journal of Chinese Agricultural Mechanization, 2016; 37(10): 70-74, 90. (in Chinese)

[84] Huang P, Tao L, Gu M, Quan Y. Experimental study of wind loads on gable roofs of low-rise buildings with overhangs. Front Struct Civ Eng, 
2018; 12(3): 300-317.

[85] Wang X J, Li Q S, Yan B W, Li J C. Field measurements of wind effects on a low-rise building with roof overhang during typhoons. J Wind Eng Indus Aerodyn, 2018; 176: 143-157.

[86] Wang X, Li Q, Li J. Field monitoring and wind tunnel study of wind effects on roof overhang of a low - rise building. Struct Contr Health Monit, 2019; 27(3). doi: 10.1002/stc.2484.

[87] Xie X Y, Chen K. Simulation test of wind load characteristics of South China type single-span plastic greenhouse. Transactions of the CSAE, 2000; 16(5): 90-94. (in Chinese)

[88] Huang P, Tao L, Gu M, Quan Y. Wind effects of architectural details on gable-roofed low-rise buildings in southeastern coast of China. Adv Struct Eng, 2014; 17(11): 1551-1565.

[89] Shirzadi M, Mirzaei P A, Tominaga Y. RANS model calibration using stochastic optimization for accuracy improvement of urban airflow CFD modeling. J Build Eng, 2020; 32: 101756. doi: 10.1016/j.jobe.2020. 101756.

[90] Heinz S. A review of hybrid RANS-LES methods for turbulent flows: Concepts and applications. Prog Aeronaut Sci, 2020; 114: 100597. doi: 10.1016/j.paerosci.2019.100597.

[91] Takakura T. Research exploring greenhouse environment control over the last 50 years. Int J Agric \& Biol Eng, 2019; 12(5): 1-7.

[92] Pakari A, Ghani S. Evaluation of a novel greenhouse design for reduced cooling loads during the hot season in subtropical regions. Sol Energy, $2019 ; 181: 234-242$.

[93] McCartney L, Lefsrud M G. Field trials of the Natural Ventilation Augmented Cooling (NVAC) greenhouse. Biosyst Eng, 2018; 174: 159-172.

[94] Espinoza K, López A, Valera D L, Molina-Aiz F D, Torres J A, Peña A. Effects of ventilator configuration on the flow pattern of a naturally-ventilated three-span Mediterranean greenhouse. Biosyst Eng, 2017; 164: 13-30.

[95] Neto J G V, Soriano J. Distribution of stress in greenhouses frames estimated by aerodynamic coefficients of Brazilian and European standards. Sci Agr, 2016; 73(2): 97-102.

[96] Moriyama H, Sase S, Uematsu Y, Yamaguchi T. Wind pressure coefficient of a pipe-framed greenhouse and influence of the side gable openings using a wind tunnel. Journal of the Society of Agricultural Structures, Japan, 2008; 38(4): 237-248.

[97] Wang J, Ding W M, Wu Y F. Wind tunnel test of wind pressure distribution on mutual insert multi-greenhouse roof. Transactions of the CSAE, 2008; 24(1): 230-234. (in Chinese)

[98] Kuroyanagi T. Investigating air leakage and wind pressure coefficients of single-span plastic greenhouses using computational fluid dynamics. Biosyst Eng, 2017; 163: 15-27.

[99] Yi Q, Wang X, Zhang G, Li H, Janke D, Amon T. Assessing effects of wind speed and wind direction on discharge coefficient of sidewall opening in a dairy building model - A numerical study. Comput Electron Agric, 2019; 162: 235-245.

[100] Dong X, Ye J H, Ding J M. Review of destructive vortices and vortex-induced wind pressures on low-rise buildings. J Build Struct, 2018; 39(1): 1-10. (in Chinese)

[101] Kozmar H. Surface pressure on a cubic building exerted by conical vortices. J Fluids Struct, 2020; 92: 102801. doi: 10.1016/j.jfluidstructs.2019.102801.

[102] Yang Z Q, Zhang B, Xue X P, Huang C R, Zhu K. The wind tunnel test of plastic greenhouse and its surface wind pressure patterns. Acta Ecologica Sinica, 2012; 32(24): 7730-7737.

[103] Yang Z Q, Li Y X, Xue X P, Huang C R, Zhang B. Wind loads on single-span plastic greenhouses and solar greenhouses. HortTechnology, 2013; 23(5): 622-628.

[104] Li N, Xue X P, Li H Y. The risk assessment of wind disaster of greenhouse in Shandong province based on information dissemination theory. Journal of Meteorology and Environment, 2018; 34(5): 149-155. (in Chinese)

[105] Vieira Neto J G, Soriano J. Computational modelling applied to predict the pressure coefficients in deformed single arch-shape greenhouses. Biosyst Eng, 2020; 200: 231-245. 